\title{
Study on wood surface colored electroless Ni process
}

\author{
Yanfei PAN ${ }^{1, a}$, Yu WANG ${ }^{1, b}$ and Jintian HUANG ${ }^{1, c^{*}}$ \\ ${ }^{1}$ college of material science and art design, Inner Mongolia agricultural university, Hohhot 010018 , \\ Inner Mongolia, China \\ a1440643219@qq.com, b4 499436197@qq.com, cjintian_h@163.com \\ * Jintian HUANG
}

Keywords: wood surface; electroless Ni; dyeing; ammonium molybdate

Abstract. In order to meet the requirements of decoration on a variety of colors, this study with ammonium molybdate and sodium phosphite as coloring liquid ingredient made use of wood through electroless $\mathrm{Ni}$, dyeing to change the wood surface color single situation after electroless plating to find the best technology of color chemical plating coatings. The particles morphology and the surface morphology of coatings were investigated by scanning electron microscopy (SEM). The results showed that electroless plating $\mathrm{Ni}$ on the wood surface, the concentration of ammonium molybdate and sodium phosphate and time of coloring color had great influence on coatings color; And ultimately the optimal process about concentration range of components as well as the time was 1.5-2.5 g/L ammonium molybdate, sodium phosphite 4.5-7.0 g/L, $15 \mathrm{~min}$ of the color plating time, respectively.

\section{Introduction}

Currently, electroless Ni-P on the metal surface research mainly in the plating process, formation mechanism, organization structure, management of plating solution and composite plating ${ }^{[1]}$. Because of electroless Ni-P coating surface approximation white, sometimes slightly pale yellow ${ }^{[2]}$, with the improvement of people's living standard, household and office, instrumentation, equipment, parts and so on all need beautiful and high quality decorative durable coating, and colored electroless plating has a good application prospect ${ }^{[3]}$. Through electroless plating with some colour, this is the color chemical plating. Over the years, chemical nickel plating layer structure, performance, and the influence factors of the coating process were studied in-depth to obtain a series of important achievements $^{[4]}$. At present, there are few report about the color of chemical plating and electroless Ni-P plating color processing technology ${ }^{[5,6]}$. Especially wood surface color electroless relevant research work is less, with the development of the economy, in our daily life, decorating the life with the color of electroless plating has been expected by people ${ }^{[7]}$, and so on coated color layer of wood has a good application prospect.

This study made some exploratory work on wood color electroless Ni composite coatings process.

\section{Materials and equipments}

Reagents and materials. Nickel sulfate, sodium hypophosphite, ammonium molybdate, sodium citrate, thiourea, ammonia are analyzed for pure, Yang wooden fast.

Equipments. BS110S type electronic balance, S212B-1-5L thermostatic vacuum stirring reactor, PHS-2CA type precision acidity meter, DH-101-2S type electric thermostatic drying oven, W201B electrothermal constant temperature water bath pot, tray balance, S-3400N scanning electron microscope. 


\section{Results and discussions}

\section{The electroless Ni on wood surface coating effect on color}

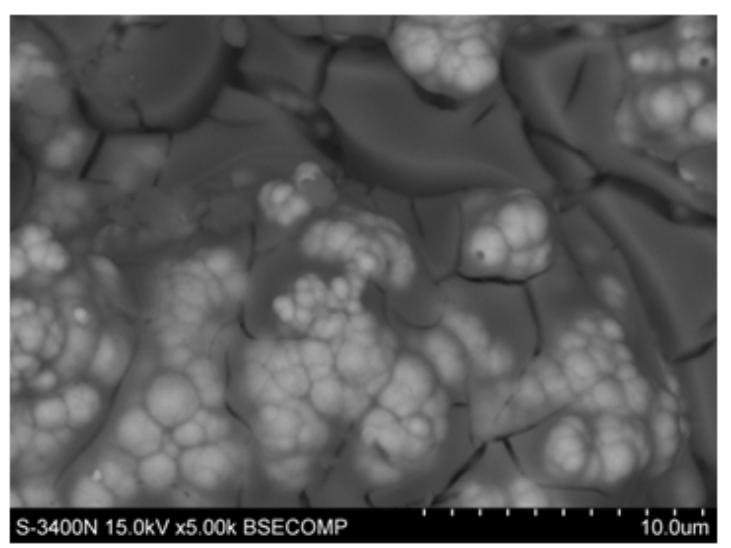

Fig.1 without coloring wood surface

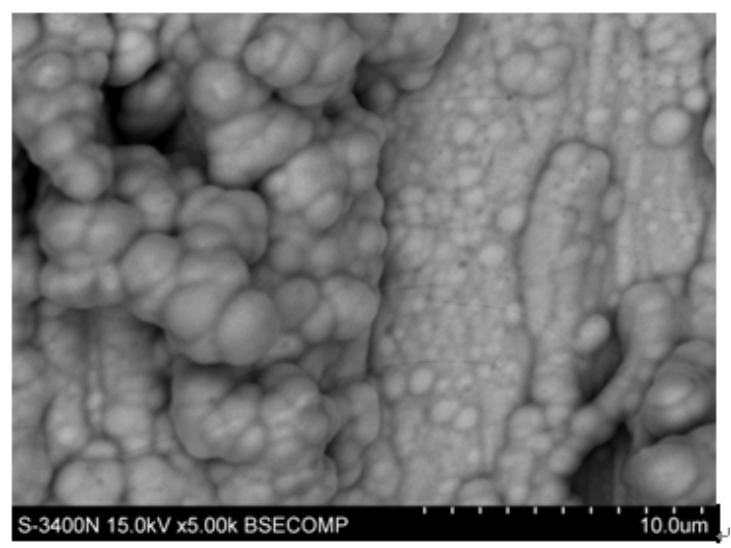

Fig.2 wood surface coloring

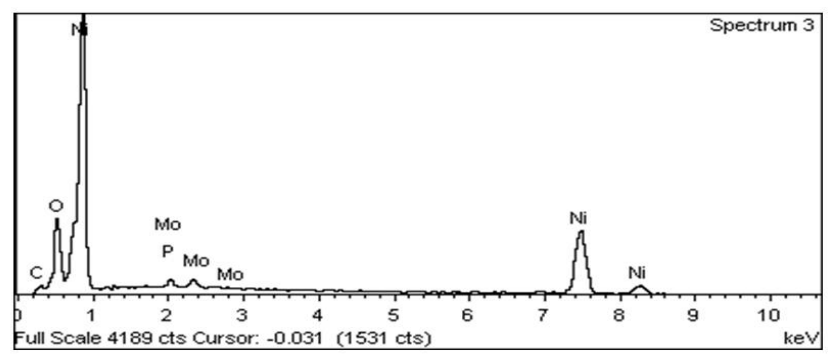

Fig.3 element ingredient analysis of metalized wood

Coloring process is after electroless Ni-P on the wood surface, so the quality of electroless Ni-P will produce certain influence on the effects of shading. Experimental results show that electroless Ni-P coating uniformity, smooth surface, uniform metallic luster, under the condition of the same color, easy to obtain a uniform color. Figure 1 and Fig. 2 were before coloring and after coloring color wood surface morphology comparison. From Fig.1, the undulating particles scattered on the coatings surface through coloring and there are more black P atoms (Fig.3). Figure 2 after the rainbow color coating on the surface of the smoothness and uniformity were greatly improved. Investigating its reason, electroless Ni-P coating uniformity, smooth surface in favor of the deposition of the homogeneous molybdenum atoms, and uniform coating on the surface of the Ni-P forces between atoms and Mo are balanced, the uniform deposition, the reflection of light and a series of physical property is better, so the stand or fall of electroless Ni-P surface coating have important influence on coloring.

\section{The influence of ammonium molybdate concentration on color}

Table.1 coloring solution of ammonium molybdate content is $2.0 \mathrm{~g} / \mathrm{L}$ with wood surface color changing with time

\begin{tabular}{lllllll}
\hline 5 min & 10 min & 15 min & 20 min & 25 min & 30 min & 35 min \\
\hline pale red & pale green & rainbow & dark red & black & black & black \\
\hline
\end{tabular}


In table 1, when joining the ammonium molybdate is $2.0 \mathrm{~g} / \mathrm{L}$, color of electroless plating on wood surface color changes uniformly. The colour is easy controlled and color is better.Therefore, the experiment of the amount of ammonium molybdate is $1.5-2.5 \mathrm{~g} / \mathrm{L}$. Experiments show that the coating color of the rainbow color mainly depends on the content of Mo atoms, thus the amount of Mo atom directly affects the emergence of the rainbow color of coating.

\section{The influence of concentration of sodium phosphite on color}

Table. 2 coloring solution of sodium hypophosphite content is $6.0 \mathrm{~g} / \mathrm{L}$ with wood surface color changing with time

\begin{tabular}{cllllll}
\hline $5 \mathrm{~min}$ & $10 \mathrm{~min}$ & $15 \mathrm{~min}$ & $20 \mathrm{~min}$ & $25 \mathrm{~min}$ & $30 \mathrm{~min}$ & $35 \mathrm{~min}$ \\
\hline pale yellow & pale red & rainbow & rainbow & violet & dark red & black \\
\hline
\end{tabular}

In table 2, when sodium phosphite is $6.0 \mathrm{~g} / \mathrm{L}$, ammonium molybdate and sodium phosphite concentration ratio up to $1: 3$, color changes evenly after electroless plating on the surface of the wood surface and rainbow color appears for a long time with the better color effect, easy control. Therefore, this experiment, sodium phosphate dosage is controlled between 4.5 and $4.5 \mathrm{~g} / \mathrm{L}$.

\section{The influence of electroless Ni on color}

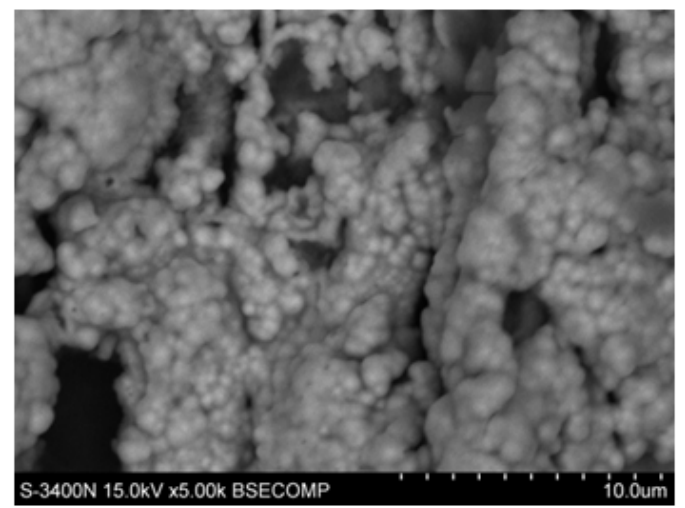

Fig.4 (Rainbow)

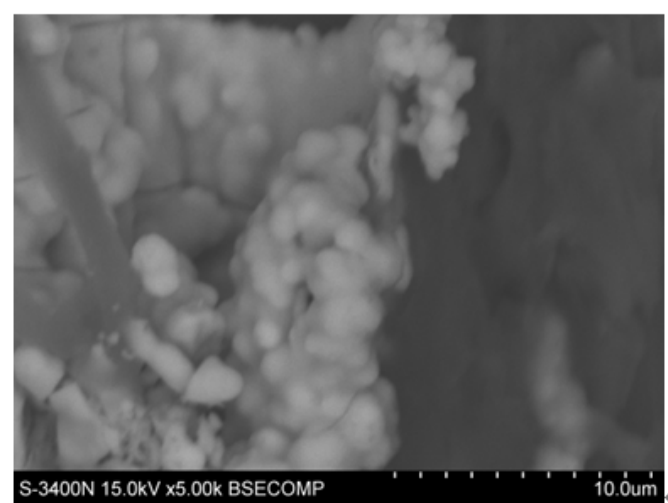

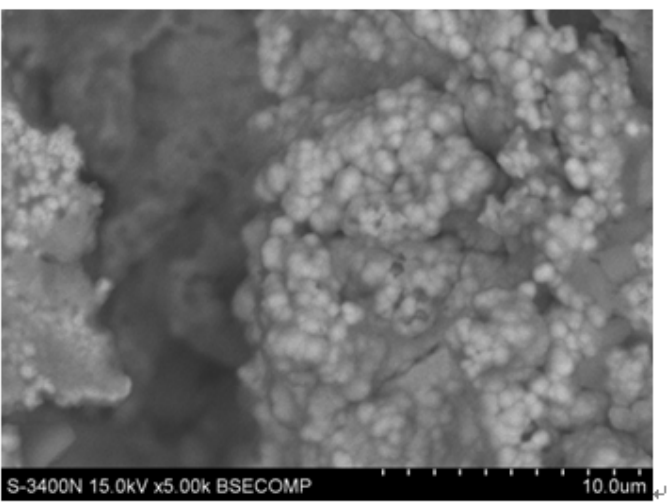

Fig.5 (purple)

Fig.6 (black) 
Table.3 The color change of the different period

\begin{tabular}{cccccc}
\hline Time $(\min )$ & 5 & 10 & 15 & 20 & 25 \\
\hline Colour & violet & yellow & rainbow & pink & black \\
\hline
\end{tabular}

Through the table 3, it is clearly that after coloring of the color of the wood surface and time are closely linked with the different time and different colors. By comparing the Fig.4, Fig.5 with Fig.6, when the time is $15 \mathrm{~min}$, wood surface shows the rainbow color and SEM image shows the Mo atoms on the surface of the timber distribution more uniform. Therefore, this experiment reasonable color plating time is $15 \mathrm{~min}$. Time length will affect the Mo atoms precipitation amount, which will affect the film thickness. And film thickness different index of refraction of light is also different leading to different time different colors.

\section{Summary}

(1) Wood surface electroless $\mathrm{Ni}$, ammonium molybdate, sodium phosphite concentration and time of coloring colour changes have a certain influence on coloring.

(2) To obtain the optimal concentration range of components, as well as the time and processt are 1.5-2.5 g/L ammonium molybdate, sodium phosphite 4.5-7.0 g/L, the color plating time $15 \mathrm{~min}$, respectively.

(3) When color plating time is $15 \mathrm{~min}$, wood surface shows the rainbow color and SEM image shows the Mo atoms on the surface of the timber distribution more uniform.

\section{Acknowledgements}

This work was supported by the activation of wood electroless nickel plating technology (2013 patent promotion transformation project) and science research innovation projects of the Inner Mongolia Autonomous Region for graduate under grant no.B20141012902Z.

\section{Corresponding Author}

Jintian Huang, jintian_h@163.com, 13947125748, 0471-4309208.

\section{References}

[1] N. Li, The chemical plating practical technology, Bei Jing, 2004.

Reference to a book:

[2] X.X. Jiang, W. Shen, The theory and practice of the chemical plating, Bei Jing, 2000.

Reference to a chapter in an edited book:

[3] L.Q. Zhu, G.Y. Yang, J.H. Peng, New colored electroless nickel plating technology was studied, Electroplating and environmental protection, 1997, pp. 18-19.

[4] Z.J.Qu, G.L. Huang, Colored electroless plating ni-p alloy plating research, Surface technology, 2007, pp.40-42.

[5] Y.Zhang, The electroless Ni-P plating color processing, Journal of daqing petroleum institute of learning, 2003, pp.39-41.

[6] C.Y.Jiang, G.L.Huang, Colored electroless Ni-P craft research, Application of chemical industry, 2007, pp.1252-1254.

[7] S.Y.Shi, The research progress of new type of $\mathrm{Ni}$ - P alloy coating material, Journal of jiamusi institute of education, 2012, pp. 402-405. 